\title{
Autoantibodies to GFAP (glial fibrillary acidic protein) and to dopamine in patients with acute and chronic ce- rebrovascular disorders
}

\author{
Pavel R. Kamchatnov ${ }^{1}$, Alexander V. Chugunov ${ }^{1}$, Natalia Yu. Ruleva ${ }^{2 *}$, Sergey F. Dugin ${ }^{2}$, Daria \\ A. Basse ${ }^{1}$, Burliat A. Abusueva1, Luidmila I. Buriachkovskaya ${ }^{2}$, Evgeny I. Gusev ${ }^{1}$
}

${ }^{1}$ Russian State Medical University, Moscow, Russia; *Corresponding Author: nruleva@cardio.ru;

${ }^{2}$ Russian Cardiology Research and Production Complex, Moscow, Russia.

Received 27 September 2010; revised 8 October 2010; accepted 13 October 2010

\begin{abstract}
We have studied the level of autoantibodies to neurospecific proteins and neurotransmitters in patients with different forms of ischemic brain lesion. 49 patients with acute (ishemic stroke) and chronic cerebrovascular disease, 14 patients with ishemic heart disease and control group (35 healthy subjects) were investigated. The serum level of autoantibodies to glial fibrillary acidic protein (GFAP) and to dopamine (D) was determinated by ELISA. The content of autoantibodies to GFAP and D in patients with ischemic heart disease was practically identical. The patients with acute and chronic cerebrovas-cular diseases had the significally increased level of autoantibodies. The level of autoantibodies to GFAP in patients with acute vascular accidents (ischemic stroke) with favorable outcome was significantly higher than in patients with chronic cerebral ischemia. The obtained data allowed us to consider serum level of autoantibodies to GFAP as a marker of ischemic brain lesion, and to suppose further potential role of this autoantibodies in cerebrovascular disease progression.
\end{abstract}

Keywords: Acute and Chronic Cerebrovascular Diseases; Ischemic Stroke; Autoantibodies to Glial Fibrillary Acidic Protein; Autoantibodies to Dopamine

\section{INTRODUCTION}

Widespread distribution of cerebrovascular diseases, lack of effective therapeutic and rehabilitation strategies for patients after stroke make it necessary to develop effective and reliable methods of disease course prediction, search new ways of treatment of such patients.
Finding-out of the main elements of pathobiochemical cascade developing in acute cerebral ischemia and revelation of biochemical markers for brain tissue injury are of particular interest [1].

The evidence of correlation between type and volume of brain tissue lesion and presence of substances-biomarkers of brain tissue injury in peripheral blood was obtained [2, 3]. It was determined that concentration of glial fibrillary acidic protein (GFAP) in blood serum of patients with ischemic stroke was associated with more extensive damage volume [4,5].

GFAP is the maker for the spider cells (astrocytes) $[6,7]$. Astrocytes, lied in the first layer of neocortex, form border-line neuroglial membrane, their long processes reach deep into cortex and run to its middle layers assisting in formation of perivascular adjoined membranes, representing important part of the blood-brain barrier (BBB).

Experiments ascertained that GFAP execute structural functions, besides, it participates directly in restoration processes after ischemic or traumatic brain lesion $[8,9]$. The formation of the hypertrophied processes of spider cells in the damaged area is closely associated with activation of synaptogenesis [10]. Deficit of GFAP, disturbance of its phosphorylation are associated with new synaptic connection forming damage, predominantly at the dorsolateral prefrontal cortex and hippocampus in patietns with mental disorder, the most prominent in the elderly $[11,12]$.

Increase of concentration of autoantibodies to GFAP in cerebrospinal fluid and in peripheral blood is connected with brain tissue damage and abnormality of BBB. High level of such autoantibodies was detected in some neurodegenerative and mental diseases [13-15], brain injury and ischemic lesion $[16,17]$.

Currently, role of autoantibodies to neurospecific protein, e.g. GFAP, is explored insufficiently. It's suggested 
that their concentration may reflect processes of elimination of damaged brain tissues from the lesion area, occurring through the disruption of BBB [17-20].

The role of neurotransmitters in pathogenesis of acute brain ischemia is intensively studying now. Dopamine release during acute ischemia activates production of free radicals [21], induces apoptosis [22]. As acute, as delayed ischemic neuronal death, associated with dopamine release, is mediated_by exitotoxic effects of glutamate [20]. Rise of dopamine concentration in synaptic gap in experimental conditions (highly excesses normal level-about $100 \mu \mathrm{M}$ ) is accompanied by toxic effects [23].

Nevertheless in distant period of ischemia dopamine can take part in processes of restoration. Some data exists that regress of spastic paresis after stroke is faster with standard treatment combined with L-DOPA [5,24]. Its positive effect may be due to long-term memory facilitation and consolidation on different levels [13]. It is proposed, that neurological restoration may be the sequence of the elevation of central noradrenalin pool which precursor is dopamine [9].

There is lack of data about autoantibodies to nerotrasmitters. Existing reports about elevation of level of antibodies to dopamine and its receptors in cerebrospinal fluid in some neurological (Parkinson disease, Alzheimer disease, pain syndromes) and psychiatric (alcohol and narcotic addictions, suicide behavior, depression) disorders $[18,25,26]$. The existence of antibodies is attributed to immune system disregulation, accompanied central nervous system disorders, but less is known about changes of antibodies concentration and their role genesis of different syndromes.

Our work objective was evaluation of diagnostic significancy of autoantibody to GFAP and to dopamine (D) in patients with different forms of cerebrovascular diseases.

\section{PATIENTS AND METHODS}

63 patients with cerebrovascular and ischemic heart diseases were investigated. Verification of cerebrovascular disease was provided by MRI, Doppler ultrasonography of carotid and intracranial arteries. The diagnosis of coronary heart disease was confirmyd by routine ECG and 24-hour monitoring, treadmill tests and in some patients with help of coronary angiography. The patients with acute or chronic inflammatory diseases, acute myocardial infarction, who undergone coronary revascularization and angioplasty for the period of last 6 months, suffering from cardiac anomalies, severe arterial hypertension, congestive heart failure, decompensated type 2 diabetes mellitus were excluded.

The first group (group 1) consisted of 22 patients with chronic cerebral ischemia caused by microangiopathy in consequence of the arterial hypertension $(n=9)$ and its combination with type 2 diabetes mellitus $(n=4)$, isolated occlusive lesion of large cranial arteries $(n=4)$ and simultaneous lesion of small and large arteries $(n=5)$. There were 13 men and 9 women at age from 52 to 71 (mean age was $59.7 \pm 6.9 \mathrm{yrs}$ ) in this group. Any of these patients had not any incident of acute cerebral ischemia (TIA, stroke) over last 6 months.

The second group (group 2) consisted of 14 patients with coronary heart disease (stable exertional angina, function class I-II), there were 8 men and 6 women among them at age of 49-73 yrs (mean age was $62.2 \pm$ $5.7 \mathrm{yrs}$ ) without clinical/paraclinical sings of cerebrovascular disease.

The third group (group 3) consisted of 27 patients with acute carotid ischemic stroke (in the right carotid artery in $15 \mathrm{pts}$, and in the left - in $12 \mathrm{pts}$ ), the presence of infarct focus was proven by neurovisualization or postmortem examination $(n=6)$. There were 15 men and 12 women among the participants of this group at age from 52 to 84 (mean age was $64.6 \pm 6.9 \mathrm{yrs}$ ). All of these patients were admitted to hospital during the first 24-hour of disease. There was the atherotrombotic stroke in 8 pts, cardioembolic stroke in 7 pts. The main reason of stroke in 2 participants was the small vessels disease and combination of the mechanisms in 10 patients. Total infarct at the carotid system was diagnosticated in $7 \mathrm{pts}$, partial - in 12, lacunar stroke was presented in 8 pts.

There recovery of neurologic deficiency in 15 patients (subgroup 3a) was marked, indicated by increase of average score in European scale of stroke (ESS) on 10 points during 21 days of disease. In the rest of 12 patients (subgroup 3b) severity of focal deficiency remained stable or fatal case occurred (causes of the latter one were progressive brain edema, concomitant ignifymatory pulmonary diseases, acute coronary insufficiency).

Control group consisted of 35 healthy subjects (16 men and 19 women) at age 32-54 yrs (mean age was $47.2 \pm 4.6 \mathrm{yrs}$ ) without central nervous system diseases and without chronic inflammatory diseases.

Venous blood samples were collected by standart procedure, in case of acute stroke - in the first 24-hours after disease onset, and the serum samples were stored at $-70^{\circ} \mathrm{C}$.

The serum level of autoantibodies to GFAP and to D was determinated by ELISA as was described earlier [3, 30]. 96-well microtiter plates were coated with GFAP or conjugate Dopamine-BSA $(5 \mu \mathrm{g} / \mathrm{ml}$ in carbonate buffer over the night). As the standard the serum of a healthy adult subject (at age of 34) without signs of somatic, neurologic, endocrine, infectious and inflammatory diseases was used. All the samples and standart were di- 
luted 1:25 with PBS, containing 1\% BSA and $0.05 \%$ Tween-20, and added to the appropriate wells. The plates were incubated for $2 \mathrm{~h}$ at room temperature. For the detection of autoantibodies the secondary rabbit anti-human antibodies conjugated with horseradish peroxidase (Imtek, Moscow) were used. The level of autoantibodies was estimated as a ratio of optical density of sample to the optical density of standard and was expressed in relative units.

Statistic analysis was carried out using standard package of SPSS 13.0. Research data in the each group are represented as mean observation \pm standard error of the mean. Multivariate comparisons were performed using of Student t-test with Bonferroni and Newmen-Kales adjustments. Differences were considered to be ignifycant for $\mathrm{p}<0.05$.

\section{RESULTS}

The concent of autoantibodies to GFAP and to dopamine in patients with ischemic heart disease (group 2) and in control group had been appeared to be practically identical (Table 1). Significant increased level of autoantibodies in comparison with the group 2 and the control group was detected in patients with chronic cerebral ischemia stroke (groups 1 and 3). Autoantibodies to GFAP level in patients with stroke were exceeding one in patients with chronic cerebral ischemia more than in one and half times, but it failed to reach, however, significance level. The contents of autoantibodies to Dopa- mine in patients with stroke and chronic cerebral ischemia were practically identical.

Essential differences in contents of autoantibodies in patients with chronic cerebrovascular disease with different focal deficit and the main clinical syndrome were not detected.

Interesting results were obtained when the group of patients with acute stroke was divided into two subgroups (Table 2). The levels of autoantibodies to GFAP and Dopamine were higher $(\mathrm{p}<0.05)$ in patients with clinical improvement and regression on focal deficiency towards 21 days of disease (subgroup 3a) in comparison with those in patients who had inconsiderable neurologic functions recovery (subgroup 3b). Moreover level of autoantibodies to GFAP in patients with favorable course of stroke was higher $(\mathrm{p}<0.05)$ than in patients with chronic cerebrovascular diseases.

In order to study the influence of episodes of repeated acute cerebral ischemia on content of autoantibodies to GFAP the group of 15 patients who had repeated ischemic stroke $(\mathrm{n}=11)$ or who had the transient ischemic attacks before stroke development was formed (Table 3). The level of autoantibodies in patients who had undergone repeated episodes of acute cerebral ischemia, was differed significally from the autoantibodies level in control group, but there were no significant differences in comparison with group of patients with chronic cerebral ischemia.

Table 1. The levels of autoantibodies to GFAP and Dopamine in patients with chronic cerebral ischemia, stroke, coronary heart disease ischemic heart disease and in control group.

\begin{tabular}{|c|c|c|c|c|}
\hline & $\begin{array}{c}\text { Group 1 } \\
\text { Chronic cerebrovascular } \\
\text { disease }(\mathrm{n}=22)\end{array}$ & $\begin{array}{l}\text { Group } 2 \\
\text { Coronary heart disease } \\
(\mathrm{n}=14)\end{array}$ & $\begin{array}{l}\text { Group } 3 \\
\text { Stroke } \\
(\mathrm{n}=27)\end{array}$ & $\begin{array}{l}\text { Control group } \\
\quad(\mathrm{n}=35)\end{array}$ \\
\hline $\begin{array}{l}\text { Autoantibodies to GFAP, } \\
\text { rel.un. }\end{array}$ & $1.42 \pm 0.07$ & $0.95 \pm 0.04^{* \#}$ & $2.27 \pm 0.30$ & $0.95 \pm 0.03^{* \#}$ \\
\hline $\begin{array}{l}\text { Autoantibodies to Dopa- } \\
\text { mine, rel.un. }\end{array}$ & $1.51 \pm 0.09$ & $0.93 \pm 0.05^{* \#}$ & $1.55 \pm 0.09$ & $0.91 \pm 0.05^{* \#}$ \\
\hline
\end{tabular}

Table 2. The levels of autoantibodies in subgroups of patients with stroke, in patients with chronic cerebral ischemia and in control group.

\begin{tabular}{lcccc}
\hline & $\begin{array}{c}\text { Subgroup 3a } \\
(\mathrm{n}=15)\end{array}$ & $\begin{array}{c}\text { Subgroup 3b } \\
(\mathrm{n}=12)\end{array}$ & $\begin{array}{c}\text { Chronic cerebrovascular } \\
\text { diseases }(\mathrm{n}=22)\end{array}$ & Control group $(\mathrm{n}=35)$ \\
\hline $\begin{array}{c}\text { Autoantibodies to GFAP, rel.un. } \\
\text { Autoantibodies to Dopamine, } \\
\text { rel.un. }\end{array}$ & $2.98 \pm 0.45^{*}$ & $1.29 \pm 0.08^{\#}$ & $1.42 \pm 0.07^{*}$ & $0.95 \pm 0.03$ \\
\hline
\end{tabular}

*.- difference is significant in comparison with control group $(\mathrm{p}<0.05)$, ${ }^{\#}$ - difference is significant in comparison with subgroup $3 \mathrm{a}(\mathrm{p}<0.05)$. 
Table 3. The levels of autoantibodies to GFAP in patients with repeated acute cerebral ischemia, in patients with chronic cerebral ischemia and in control group.

\begin{tabular}{lccc}
\hline & $\begin{array}{c}\text { Repeated episodes of acute cere- } \\
\text { bral ischemia } \\
(\mathrm{n}=15)\end{array}$ & $\begin{array}{c}\text { Group 1 } \\
\text { Chronic cerebral ischemia } \\
(\mathrm{n}=22)\end{array}$ & $\begin{array}{c}\text { Control group } \\
(\mathrm{n}=35)\end{array}$ \\
\hline Autoantibodies to GFAP & $1.53 \pm 0.12^{*}$ & $1.42 \pm 0.07^{*}$ & $0.95 \pm 0.03$ \\
\hline
\end{tabular}

*.- difference is significant in comparison with control group $(\mathrm{p}<0.05)$.

\section{Discussion}

It was discovered, that increased serum levels of autoantibodies to GFAP and to Dopamine are specific to different forms of ischemic brain lesion (regardless of main clinical syndrome), as distinct from ischemic lesion of the other organs, in particular coronary heart disease. The level of autoantibodies to GFAP in patients with acute vascular accidents (ischemic stroke) with favorable outcome was significantly higher than in patients with chronic cerebral ischemia. It is interesting, that the level of autoantibodies to GFAP in patients who had undergone former episode of acute cerebral ischemia (stroke and/or transient ischemic attack), exceeded test scores, but was not different from such one in patients with chronic cerebral ischemia without episodes of acute cerebral ischemia. Ten this patients with stroke (out of 15) had unfavorable outcome of the diseases. The obtained data allowed us to consider serum level of autoantibodies to GFAP as a marker of ischemic brain lesion, and to suppose further potential role of this autoantibodies in cerebrovascular disease progression.

The data about serum level of autoantibodies to Dopamine were less informative. The contents of such autoantibodies in patients with acute and chronic cerebral ischemia did not differ from each other. Significant increased levels of autoantibodies to Dopamine as and to GFAP appeared to be associated with favorable outcome of stroke in comparison with those in patients who had inconsiderable neurologic functions recovery. Our previous data [27] give evidence about correlation of high level of autoantibodies to Dopamine in the first day after stroke onset and favorable functional outcome of the disease. The physiological role of autoantibodies to Dopamine and serotonine for today is unknown. Autoantibodies to neurotransmitters may constitutevly expressed by non-activated B-cells $[1,2]$. This autoantibodies can be not only the markers of monoaminoergic systems disorders, but also can play some regulatory roles in common neuro-immune-endocrine system. Our data indirectly supports this point of view.

Relation between some neurospecific proteins serum concentration and the volume of brain lesion has been proved conclusively at the present time, at the same time there are far less data about role of autoantibodies to neurospecific proteins in cerebral pathology, about their clinical relevance and prognostic value in patients with cerebrovascular disease. There are experimental findings that the initiation of autoimmune process is possible in case of damage of $\mathrm{BBB}$ and in consequence of contact of neurospecific proteins with immune blood cell. Role of this autoimmune process has not been detected finally, so a fact of such contact of neurospecific proteins with immune competent cell in itself does not mean the initiation of autoimmune process [28]. In such a way clinical significance of production of immunoglobulins to some cerebral proteins taking place after stroke remains conclusively unknown [23,26,28].

At present time there are experimental findings that immunization of laboratory animals by some neurospecific antigens may have protective effect on brain in experimental models of cerebral lessions, in particular, Alzheimer's disease, prion diseases and reduce the expression of brain trauma consequence [24,29].

There is an evidence that the serum level of neurospecific autoantibodies in elderly patients with dementia (both of vascular and Alzheimer's types) is higher, than in patients of the same age without cognitive decline, and this increase is not peculiar of nosological entity of pathology but may reflect the condition of BBB [22,30]. Taking into account the peculiarities of GFAP molecule configuration, its physical, chemical and electric properties it is suggested that rise of level of autoantibodies to GFAP in the blood serum is not connected with penetration of this protein through BBB but it reflects the disregulation processes at the organism [21].

Poletaev et al. [18] suppose that autoantibodies to neurospecific proteins may play role in the organism in two ways. If such autoantibodies, probably, perform protective and compensatory functions after undergoing episode of acute cerebral ischemia, then the character of changing in patients with schizophrenia have to suppose rather their pathogenetic role. Our results support this hypothesis. Earlier we ascertained that higher levels of autoantibodies to GFAP in patients with acute ischemic stroke was associated with favorable outcome of disease and more completed recovery of disturbed functions [19]. This fact allows suggesting a positive role of autoantibodies in acute conditions. Presence of autoantibodies to GFAP in patients with chronic cerebral ischemia regardless of character and expression of neurological deficit 
allows us to assume that in case of chronic cerebrovascular disease autoantibodies doesn't perform protective functions.

Further researches are needed for ascertainment of role of autoantibodies to neurospecific proteins and neurotransmitters in patients with different forms of cerebrovascular disorders, including cases of acute cerebral ischemia. The question if autoantibodies are only "witness" of processes occuring in ischemic brain area or they perform certain functions related with processes of destruction and reparation at the impaired brain tissue remains in abeyance.

\section{REFERENCES}

[1] Gusev, E.I. and Skvortsova, V.I. (2003) Brain ischemia. Kluwer Academic Publishers, New York.

[2] Anand, N. and Stead, L. (2005) Neuron-specific enolase as a marker for acute ischemic stroke: A systematic review. Cere-Brovascular Diseases, 20, 213-219.

[3] Foerch, C., Singer, O., Neumann-Haefelin, T., et al. (2005) Evaluation of serum $\mathrm{S} 100 \mathrm{~B}$ as a surrogate marker for long-term outcome and infarct volume in acute middle cerebral artery infarction. Archives of Neurology, 62, 1130-1134.

[4] Foerch, C., Curdt, I., Yan, B., et al. (2006) Serum glial fibrillary acidic protein as a biomarker for intracerebral haemor-rhage in patients with acute stroke. Journal of Neurology, Neurosurgery, and Psychiatry, 77,181-184.

[5] Herrmann, M., Vos, P., Wunderlich, M., et al. (2000) Release of glial tissue-specific proteins after acute stroke: A comparative analysis of serum concentrations of protein S-100B and glial fibrillary acidic protein. Stroke, 31, 2670-2677.

[6] Korzhevskii, D.E., Otellin, V.A. and Grigor'ev, I.P. (2005) Glial fibrillary acidic protein in astrocytes in the human neocortex. Neuroscience and Behavioral Physiology, 35, 789-792.

[7] Schroeter, M., Schiene, K., Kraemer, M., et al. (1995) Astroglial responses in photochemically induced focal ischemia of the rat cortex. Experimental Brain Research, 106, 1-6.

[8] Aldskogius, H. and Kozlova, E. (1998) Central neuron-glial and glial-glial interactions following axon injury. Progress in Neurobiology, 55, 1-26.

[9] Kato, H., Kogure, K., Araki T. and Itoyama, Y. (1994) Astroglial and microglial reactions in the gerbil hippocampus with induced ischemic tolerance. Brain Research, 664, 69-76.

[10] Wilhelmsson, U., Li, L., Pekna, M., et al. (2004) Absence of glial fibrillary acidic protein and vimentin prevents hyper-trophy of astrocytic processes and improves post- traumatic regeneration. Journal of Neuroscience, 24, 50165021.

[11] Si, X., Miguel-Hidalgo, J., O’Dwyer, G., et al. (2004) Age-dependent reductions in the level of glial fibrillary acidic protein in the prefrontal cortex in major depression. Neuropsychopharmacology, 29, 2088-2096.

[12] Webster, M., Knable, M., Johnston-Wilson, N., et al.
(2001) Immunohistochemical localization of phosphorylated glial fibrillary acidic protein in the prefrontal cortex and hippocampus from patients with schizophrenia, bipolar disorder, and depression. Brain, Behavior, and Immunity, 15, 388-400.

[13] Poletaev, A.B., Morozov, S.G., Gnedenko, B.B., et al. (2000) Serum anti-S100b, anti-GFAP and anti-NGF autoantibodies of IgG class in healthy persons and patients with mental neurological disorders. Autoimmunity, 32, 33-38.

[14] Sanna, G., Piga, M., Terryberry, J.W., et al. (2000) Central nervous system involvement in systemic lupus erythematosus: Cerebral imaging and serological profile in patients with and without overt neuropsychiatric manifestations. Lupus, 9, 573-583.

[15] Terryberry, J.W., Thor, G. and Peter, J.B. (1998) Autoantibodies in neurodegenerative diseases: Antigen-specific frequencies and intrathecal analysis. Neurology of Aging, 19, 205-216.

[16] Melehov, M.G., Ruleva, N.Yu., Lyucova, T.K. and Dugin, S.F. (2004) Potentiating effect of nicotine on inflammation and induction of autoantibodies in rats. Russian Physiological Journal named after Sechenov, 90, 638644.

[17] Stein, T.D., Fedynyshyn, J.P. and Kalil, R.E. (2002) Circulating autoantibodies recognize and bind dying neurons following injury to the brain. J. Neuropathol. Exp. Neurol, 61, 1100-1108.

[18] Poletaev, A.B., Alferova, V.V., Abrosimova, A.A., et al. (2003) Natural neurotropic antibodies and nervous system pathology. Neuroimmunology, 1, 11-17.

[19] Ruleva, N.Yu., Kuzin, V.M., Kamchatnov, P.R., et al. (2004) Markers of inflammation, autoantibodies to neurospecific antigens and outcome in patients with acute ischemic stroke. Journal of Neurology and Psychiatrics, 12, 43-47.

[20] Magri, G., Clerici, M., Dall'Ara, P., et al. (2005) Decrease in pathology and progression of scrapie after immunisation with synthetic prion protein peptides in hamsters. Vaccine, 23, 2862-2868.

[21] Ishida, K., Kaneko, K., Kubota, T., et al. (1997) Identification and characterization of an anti-glial fibrillary acidic protein antibody with a unique specificity in a demented patient with an autoimmune disorder. Journal of the Neurological Sciences, 151, 41-48.

[22] Mecocci, P., Parnetti, L., Donato, R., et al. (1992) Serum autoan-tibodies against glial fibrillary acidic protein in brain aging and senile dementias. Brain, Behavior, and Immunity, 6, 286-292.

[23] Bornstein, N., Aronovich, B., Korczyn, A., et al. (2001) Antibodies to brain antigens following stroke. Neurology, 56, 529-530.

[24] Moalem, G., Leibowitz-Ami, R., Yoles, E., et al. (1999) Autoimmune $\mathrm{T}$ cells protect neurons from secondary degeneration after central nervous system axotomy. Nature Medicine, 5, 49-55.

[25] Dambinova, S., Khounteev, G., Izykenova, G., et al. (2003) Blood test detecting autoantibodies to N-methyl$\mathrm{D}$-aspartate neuroreceptors for evaluation of patients with transient ischemic attack and stroke. Clinical Chemistry, 49, 1752-1762.

[26] Mor, F. and Cohen, I. (2006) How special is a pathogenic CNS autoantigen? Immunization to many CNS 
self-antigens does not induce autoimmune disease. Journal of Neuro-immunology, 174, 3-11.

[27] Ruleva, N.Yu., Dugin, S.F., Kamchatnov, P.R., Lyukova, T.K., Chugunov, A.V., Martynov, M.Yu and Gusev, E.I. (2005) Autoantibodies to dopamine and outcome after acute ischemic stroke. Neuroimmunologia, 3, 22-25.

[28] Becker, K., Kindrick, D., Lester, M., et al. (2005) Sensitization to brain antigens after stroke is augmented by lipopolysac-charide. Journal of Cerebral Blood Flow \&
Metabolism, 25, 1634-1644.

[29] Schenk, D., Barbour, R., Dunn, W., et al. (1999) Immunization with amyloid-beta attenuates Alzheimer- disease-like pathology in the PDAPP mouse. Nature, 400, 173-177.

[30] Zimmer, D.B., Chaplin, J., Baldwin, A. and Rast, M. (2005) S100-mediated signal transduction in the nervous system and neurological diseases. Cell and Molecular Biology, 51, 201-214. 